\title{
De-egocentricity and Socialization: A Study of Hinton's The Outsiders
}

\author{
Dan Shi \\ Division of English Language Education, Faculty of Education, The University of Hong Kong, Hong Kong SAR, China

\begin{abstract}
The paper addresses adolescent development in Hinton's The Outsiders as the major theme based on psychoanalytic theories. This paper aims to expound on the process of de-egocentricity and socialization of the major protagonists in Hinton's The Outsiders. The study of young adult literature was rarely undertaken from the aspects of de-egocentricity and socialization, and Hinton's The Outsiders was hardly systematically introduced by scholars in China. Thus, this paper will provide the readers with a new perspective of the understanding of adolescents' coming-of-age in Hinton's The Outsiders.
\end{abstract}

Index Terms - de-egocentricity, socialization, initiation stories

\section{INTRODUCTION}

S. E. Hinton initiates her career as an author when she was still a fifteen years old high school student in Oklahoma. Her enthusiasm for reading in her childhood stimulates her to write something realistic about what the majority of children are actually doing in their daily life instead of reading "Mary Jane Goes to the Prom" ${ }^{\circledR}$ from time to time (Hinton, 2003). Her disapproval of the biased and unrealistic depiction of children's warm and fragrant life in traditional adolescent novels inspires her to create realist young adult fiction of class conflict and gang rivalry with the appalling facts of violence, poverty, alcoholism and drug addiction. Critics appreciate Hinton's "unpretentious narrative style and her skillful development of plot and character" (Enotes, 2007). In her novels, Hinton depicts "the survival and maturation of her adolescent male protagonists, tough yet tender lower-class boys who live in and around Tulsa and who grow by making difficult decision" (Enotes, 2007). The colloquial language and realistic description enable the readers to have a vivid and authentic impression of her novels, and she has been regarded as "a representative writer in new realist young adult literature" (Zhang Ying \& Yang Qianfan, 2005, p. 54).

Irritated by the bullying of the upper-class Socs to her friend, a lower-class greaser, on their way home after class, Hinton started to figure out a story of a greaser being jumped and beaten up by the Socs while he was walking home from the movie house with no company. That is the beginning of her first novel The Outsiders which leads to significant changes in young adult literature. Hinton won a great success of this novel The Outsiders which was published during Hinton's freshman year at the university. This novel describes the rivalry between two gangs. Namely, one is the lower-class greaser living in the East Side, and the other is the upper-class Socs which is the abbreviation for the Socials who are the West Side rich kids. The conflict between each other is portrayed from the perspective of a fourteen years old boy named Ponyboy, who exposes what he witnesses and experiences of his true life in the novel The Outsiders, displaying "a heroic story of friendship and belonging" as well as an adolescent fiction of coming-of-age (Hinton, 2003, the back cover).

\section{The Process of De-Egocentricity IN THE OUTSIDERS}

The paper aims to make the most of Jean Piaget's theory of ego-centrism of childhood and adolescence to figure out the reflection of de-egocentricity which is the essence of child and adolescent development concerned in the novel The Outsiders. From the perspective of developmental psychology, the theme of coming-of-age in the novel is dug out firstly through the process of de-egocentricity analysis.

\section{A. Introduction to the Theory of Ego-centrism of Childhood and Adolescence}

Jean Piaget was a Swiss scholar who began to study intellectual development during the 1920s. He "combined the theory of zoology and epistemology (the branch of philosophy concerned with the origins of knowledge) to develop a new science that he termed genetic epistemology" (Shaffer, 2004, p. 218). And the term genetic epistemology is defined as "the experimental study of the origin of knowledge" (Shaffer, 2004, p. 218). He is now regarded as one of the most influential psychologists in the research of child and adolescent development.

The theory of ego-centrism of childhood and adolescence is of great importance in Jean Piaget's genetic epistemology. According to Piaget, "ego-centrism is the most striking deficiency that contributes to the other intellectual shortcomings." He defined ego-centrism as "a tendency to view the world from one's own perspective and to have

\footnotetext{
(1) This is a quotation from an interview attached to the novel.
} 
difficulty recognizing another person's point of view" (Shaffer, 2004, p. 232). From the book The Language and Thought of the Child written by Jean Piaget (1955/1966), he laid emphasis on "ego-centric speech" of the child characterized by "repetition, monologue and dual or collective monologue" (pp. 32-33). He further pointed out the reasons why this talk is ego-centric. That is "partly because the child speaks only about himself or herself, but chiefly because he or she does not attempt to place himself or herself at his or her hearer's point of view" (Piaget, 1955/1966, p. 32). Repetition signifies that "child repeats his or her words and syllables for the pleasure of talking, with no thought of talking to anyone, nor even at times of saying words that will make sense" (Piaget, 1955/1966, p. 32). Monologue means that "the child talks to himself as though he were thinking aloud" (Piaget, 1955/1966, p. 32). And dual or collective monologue indicates that "the point of view of the other person is never taken into account, and his or her presence serves only as a stimulus" (Piaget, 1955/1966, p. 33). He was convinced that "ego-centric speech" originated from "ego-centric thought," indicating that "the type of thought exhibited by our children seeks to adapt itself to reality, but does not communicate itself as such" (p. 64). That is to say, "ego-centric thought" and "ego-centric speech" have kept the same step, for "although he talks almost incessantly to his neighbors, he rarely places himself at their point of view and he speaks to them for the most part as if he were alone, and as if he were thinking aloud" (Piaget, 1955/1966, p. 60). This is the major characteristic of ego-centrism in the first two stages of Piaget's four stages of cognitive development. The four stages are "the sensorimotor stage (birth to 2 years), the preoperational stage (2 to 7 years), the stage of concrete operations (7 to 11 years), and the stage of formal operations (11 years and beyond)" (Piaget, 1981). Along with the disappearance of "ego-centric speech" after the second stage, Jean Piaget (1955/1966) pointed out that "after the age 7 to 8, these consequences of ego-centrism do not disappear immediately, but remain crystallized in the most abstract and inaccessible part of the mind" (p. 141). Thus, a piece of information can be derived from the statement above: ego-centrism remains in the last two stages of Piaget's four stages of cognitive development.

Adolescents become less egocentric than younger children as they are aware of the existence of others instead of just their own. In other words, scholar believes that "adolescents have gradually abandoned ego-centrism of childhood in many aspects" (Colman, 1987, p. 31). However, from the book Adolescence and Emerging Adulthood written by Jeffrey Jensen Arnett (2001), it states that "cognitive development in adolescence also leads to a new kind of ego-centrism that is distinctly adolescent" (p. 85). What does this new kind of ego-centrism refer to? Arnett (2001) has noticed that "cognitive development in adolescence includes the development of metacognition - the capability to think about thinking" (p. 85). She indicated that "this development includes the ability to think about not only your own thoughts but also the thoughts of others" (Arnett, 2001, p. 85). Finally, she pointed out that "when these abilities first develop, adolescents may have difficulty distinguishing their thinking about their own thoughts from their thinking about the thoughts of others, resulting in a distinctive kind of adolescent ego-centrism which is first put forward by Piaget" (Arnett, 2001, p. 85). In other words, adolescents are not able to figure out whether this thought belongs to their own or others. To be more specific, one will regard other's point of view with one's own way of thinking. One will consider how others will think of himself or herself, while actually others are even not aware of the thought borne in this person's mind, and it is actually the thought of one's own instead of others', resulting in the misunderstanding with each other. Thus, this paper will place emphasis on the adolescent ego-centrism at the stage of formal operations in relation to the novel The Outsiders.

\section{B. Introduction to De-egocentricity}

The concept of de-egocentricity was based on Jean Piaget's theory of ego-centrism of childhood and adolescence. The influence of ego-centrism will diminish gradually as child and adolescent grow older. That is to say, adolescents will dispose of their ego-centrism along with their coming-of-age. As Professor Qian Weiliang from Beijing Industry University suggested that "the procedure of cognitive development in childhood and adolescence is actually a process of de-egocentricity" (Qian Weiliang, 2001, p. 68). Thus, an idea can be derived from the analysis above. The process of de-egocentricity is the essence of child and adolescent development, which is featured by the understanding of others among adolescent individuals. Children and adolescents will abandon their ego-centrism when communicating with each other, trying to appreciate others' points of view and making themselves understood by others as well. This is how to fulfill the task of de-egocentricity characterized by mutual understanding among children and adolescents in order to realize the goal of coming-of-age. And this paper will focus on de-egocentricity of adolescents appearing in the novel The Outsiders.

The Outsiders portrays the clash between two gangs, greasers and Socs, with young adults as their gang members as well as being the major protagonists in the novel. Since all the major protagonists in the novel will be placed in the last stage of cognitive development which is under the influence of adolescent ego-centrism first put forward by Jean Piaget, readers can also find traits of this adolescent ego-centrism mirrored from the words and deeds of the major protagonists in the novel The Outsiders. They have undergone a transformation through the process of de-egocentricity with the epitome of understanding of others, casting off their adolescent ego-centrism ultimately.

\section{Three Greasers' De-egocentricity}

The story of The Outsiders is told by Ponyboy Michael Curtis who is a member of lower-class gang greasers on the East Side. His Mom and Dad are killed in an auto wreck and he lives with his two elder brothers named Darrel Shaynne Curtis and Jr. Soda Patrick Curtis respectively. Ponyboy prefers Soda to Darrel because Darrel "hollers at Ponyboy all the time or treats him as if he was six instead of fourteen" (Hinton, 2003, p. 2). After Ponyboy being jumped by the 
Socs while walking home alone from movie house, Darrel blames Ponyboy again for not carrying a blade with him, and Ponyboy considers "he just hollers at me and I am just another mouth to feed and somebody to holler at" (p. 18). Here, Ponyboy does not understand why Darrel hollers at him, which causes misunderstanding between siblings to some extent on account of Ponyboy's ego-centrism. He regards Darrel with his own way of thinking, failing to understand him from Darrel's point of view. Darrel himself is deprived of his college education though he is smart and bright because of his family obligation in taking good care of his brothers and making both ends meet. He has high hopes for Ponyboy whom he believes will never fail to live up to his expectation, which is beyond Ponyboy's understanding. Darrel's stern attitude towards him and requirement of him are other kinds of deep love, care and affection. Ponyboy's ego-centrism is cast off only when he finds Darrel crying with tears running down his cheeks in their reunion in the hospital. Darrel has the "same helpless and pleading look" now as he does in the funeral of their parents (p. 98). All of a sudden, Ponyboy realizes that his brother does care about him, just because "Darrel is trying too hard to make something of his younger brother Ponyboy" (p. 98). At that moment, Ponyboy accomplishes the task of de-egocentricity by realizing the importance of understanding others. During the process of transformation from ego-centrism to de-egocentricity, Ponyboy undergoes a great deal of frustration, through which he realizes the significance and value of interpersonal understanding. Casting off his bias against his brother, he manages to distinguish his thinking about his own thoughts from his thinking about the thought of his brother and succeeds in the comprehension of his brother's viewpoint as well. Finally, he immerses himself in the smoother process of coming-of-age.

Ponyboy's ego-centrism gives rise to the breakdown of his second brother Soda. In the novel, "Ponyboy loves Soda more than he has ever loved anyone, even his Mom and Dad, for Soda tries to understand and understand everything, almost" (Hinton, 2003, p. 2). However, Ponyboy himself fails to understand Soda when he runs into difficulty. He remembers "how many times had Soda started to tell me something, only to find I was daydreaming or stuck in a book? He would always listen to me, no matter what he was doing" (p. 174). Whenever Ponyboy has a row with Darrel, Soda will be a middleman. Ponyboy does not realize what Soda feels to be a middleman. He takes it for granted that Soda does not have any problems and frustrations. His ego-centrism brings about their misunderstanding with each other. Not until Soda himself speaks his mind without any hesitation for the first time do Ponyboy and Darrel come to understand Soda's vexations. Soda finally said, 'I don't know. It's just...I can't stand to hear y'all fight. Sometimes...I just have to get out or...it's like I'm the middleman in a tug o' war and I'm being split in half' (p. 175). Ponyboy tries to understand Soda's distress of breaking up with his girlfriend and his dilemma towards the conflicts between Darrel and him. Ponyboy gradually attaches great importance to others instead of only to himself and begins to give up his ego-centrism which can be regarded as his process of de-egocentricity. Under the influence of Soda's stimulating explanation, he realizes his past ego-centrism that "I had expected Darrel to do all the understanding without even trying to understand him" (p. 176). At last, three of them understand and realize, "we ought to be able to stick together against everything, and if we don't have each other, we don't have anything" (p. 176). The process of de-egocentricity enables them to realize the importance of brotherly affection.

\section{One Soc's De-egocentricity}

Unlike other Socs, Cherry Valance who is a cheerleader at school and a Soc's leader's girlfriend enjoys a friendly chat and shares the same interest with Ponyboy. Cherry and Ponyboy are both interested in watching the sunsets, but from different places. Namely, one is from the upper-class West Side, while the other is from the lower-class East Side. Though they belong to different classes, they can appreciate the same beautiful sunset. However, Cherry herself has her own ego-centrism. With the social background of being a Soc, her ego-centrism is showed in her farewell with Ponyboy. When she is about to leave and say good-bye to Ponyboy, she tells him that "if he sees her in the hall at school or someplace and don't say hi" (Hinton, 2003, p. 45). That is to say, she will not accept Ponyboy as her friend in public so as to keep her status of being a Soc. Her ego-centrism is exposed even though she is amicable towards greasers in private. She is a soc after all. However, she goes through the process of de-egocentricity as well. When greasers are beaten up by Socs again and in difficulty, she comes to help greasers on her own initiative. In the novel, she tells it to Dally that "the whole mess is her fault and that she will keep up with what is coming off with the Socs in the rumble and will testify that the Socs are drunk and looking for a fight and that you fight back in self-defense" (p. 86). At that moment, Ponyboy may realize that it is not Cherry a Soc with ego-centrism who helps them, but Cherry a dreamer fulfilling the task of de-egocentricity. At Ponyboy and Cherry's first acquaintanceship, Cherry's impression of greasers as rough and unrefined can not be easily changed even though she and Ponyboy enjoy the same interest. That's the source of Cherry's ego-centrism. She thinks of greasers with her preconceptions. However, to her surprise, through the association and contact with greasers, she finds that greasers sometimes are forced to be tough in order to defend themselves against the Socs' attack. Here, she tries to understand greasers in their shoes. Therefore, it is not hard to understand Cherry's decision of bearing witness in court to Johnny's self-defense in that murder. This specific case has well demonstrated Cherry's de-egocentricity. Seeing the sunset sensationally from the West Side, she now believes that it is also very good to see the sunset from the East Side. Her de-egocentricity ends in saying "Thanks, Ponyboy" (p. 130).

\section{Two Hostile Groups' De-egocentricity}

This novel can be considered as the rivalry between two gangs. Namely, one is lower-class greasers with greasy long hair on the East Side, and the other is the West Side rich kids Socs which is the abbreviation for the socials. "Greasers 
are almost like hoods. We steal things and drive old souped-up cars and hold up gas stations and have a gang fight once in a while," while "Socs enjoy drinking, driving nice cars, and beating up greasers" (Hinton, 2003, p. 3). Each gang has different set of values. "Greasers are more emotional, while Socs are more sophisticated" (p. 38). "Greasers usually stick together, while Socs gang up on one or two, or they rumble each other with their social clubs" (p. 29). Why is there such a gap between greasers and Socs? Their ego-centrism is part of the reason. The establishment of their own gang originates from the influence of group ego-centrism, which can be defined as a tendency to give all the priorities to the interest and benefit of their own group, failing to understand other groups' points of view. Moreover, the group ego-centrism under the background of different social contexts is composed mainly of individual ego-centrism. The members belonging to the same group consider that they are superior to those in another group. Members in the same group can share a sense of belonging but can not help generating a hostile view towards the members in the other group, because they do not put themselves in other groups' shoes. They just view the world and people from their own group's perspective and have difficulty understanding other groups' points of view, which are the exposure of their ego-centrism. However, things are changing and developing all the time. Ponyboy as the representative of greasers and Randy as the representative of Socs undergo the process of de-egocentricity so as to ease the tension between two gangs. On the one hand, according to the conversation between Ponyboy and Randy, Ponyboy has confidence in Randy that he will do the same as he does to save the kids who are being endangered by conflagration. After their friendly and peaceful conversation, Ponyboy realizes that "Socs were just guys after all" (p. 118). It is the human compassion that makes him understand that Randy will do the same thing. That is to say, the thought that both greasers and Socs are human beings enables him to understand Randy from Randy's perspective and considers him as a friend instead of an enemy even though Randy belongs to another group Socs, which betokens his abandonment of ego-centrism in this case. On the other hand, his trust in Randy is appreciated by Randy himself as well. Finally, Randy says, "thanks, kid" instead of "thanks, grease" (p. 117). The transformation from grease to kid symbolizes Randy's renunciation of ego-centrism as well. In this case, there are two different kinds of ego-centrism. One is from Ponyboy which refers to his misleading thinking towards Socs as dangerous enemies. The other is from Randy who used to regard greasers as unrefined low-class hoodlums and showed his contempt for them. Here, the process of de-egocentricity has been ascertained again.

\section{THE PROCESS OF SOCIALIZATION}

Socialization considered as a crucial phase in one's childhood is another significant concept that this paper would like to attach great importance to. Through the analysis of socialization of the major characters in this paper, readers can better understand children's long journey of coming-of-age.

\section{A. Introduction to Socialization}

In Jeffrey Jensen Arnett's (2001) Adolescence and Emerging Adulthood, she considered socialization as "process by which people acquire behaviors and beliefs of the culture they live in" (p.100). Through her further analysis, this process can bring about three outcomes. The first outcome is self-regulation, which is "the capacity for exercising self-control in order to restrain one's impulses and comply with social norms" (p. 100). Role preparation is a second outcome of socialization, which includes "preparation for occupational roles, gender roles, and roles in institutions such as marriage and parenthood" (p. 100). The last outcome of socialization is "the cultivation of sources of meaning, which provide consolation, guidance, and hope to people in confronting existential questions" (p. 100). Here, the first outcome is what will be emphasized. Another Chinese scholar thought that "socialization is a process by which human beings adapt to society and are integrated into society gradually" (Qi Lin, 2006, p. 100). The socialization discussed in this paper signifies "the process by which somebody, especially a child or an adolescent, learns to behave in a way that is acceptable to their society" (Oxford Dictionary, 2004, p. 1667). The word "way" here can be regarded as social norms which are closely related to the main theme of The Outsiders. The main protagonists undergo a complete transformation from hoodlums into promising adolescents pursuing glorious victory through valiant deed. In our daily life, "young people should always take the initiative in being accepted by their society in doing something permitted and advocated by society, prohibiting themselves from acting illegally and immorally, and when young people put the invisible regulation into effect, they actually are engaged in socialization" (Qi Lin, 2006, p. 103). That is to say, socialization means adolescents trying to comply with the social norms. It is another turning point in the development of adolescents.

\section{B. Peers as Agents of Socialization}

It is widely acknowledged that adults exert a significant influence on the development of adolescents. However, some psychologists, Jean Piaget among them, believe that "peers may contribute as much (or even more) to a child's or an adolescent's development as adults do" (Shaffer, 2004, p. 597). They consider that there are "two social worlds of childhood, one involving adult-child transactions and the other involving the society of one's peers, and that these social systems influence development in different ways" (Shaffer, 2004, p. 597). Dr. Laurence Steinberg (2005) stated his view in his work Adolescence that "contemporary societies have become configurative cultures, in which socialization of young people is accomplished not merely through contact between children and their elders but through contact between young people of the same age" (p. 172). This paper lays emphasis on socialization of adolescents within the 
influence of peers. Peers, with equal status, can easily communicate with each other. On the one hand, they can share their interests and values together. On the other hand, they should learn to "appreciate each other's perspectives, to negotiate and compromise, and to cooperate with each other" (Shaffer, 2004, p. 597). The adventure peers have gone through together spurs them on to learn from others' strength to offset their own weakness, which accompanies the development of children. The novel The Outsiders can be considered as "a heroic story of friendship and belonging" (Hinton, 2003, the back cover). The unexpected incidents taking place among peers motivate them to realize the importance of social norms, enhancing their friendship through unforgettable moral lessons drawn from their experiences, and setting up or establishing their own social values to a certain extent, which finally help fulfill the task of socialization of adolescents.

\section{Socialization between Peers among Greasers}

In the group of greasers, Johnny Cade is the second youngest adolescent besides Ponyboy. In the novel, he is described as a gloomy boy after being beaten up badly by the Socs, "he had a nervous and suspicious look in his eyes" (Hinton, 2003, p. 11). Being deprived of family affection and care, he is portrayed as "the gang's pet and everyone's kid brother" in the novel (p. 12). In Social Psychology, it states that "Lacking a positive personal identity, people often seek self-esteem by identifying with a group" (Myers, 2005, p. 351). Thus, Johnny can establish his own identity in the greasers. In the group of greasers, Ponyboy and Johnny are good friends. A complete transformation has taken place between them from that special night. Seeing movies at a drive-in, Ponyboy and Johnny come across two Soc girls. They can well communicate with each other and share their interests together, and get along with Socs harmoniously. However, on their way home, the two Soc girls run into their drunken boyfriends. They must leave with their boyfriends to prevent a fight between the Socs and the greasers. When Ponyboy comes back home late at that night, his brother Darrel is getting so annoyed that he slaps Ponyboy who has never suffered from this before and runs away on a sudden impulse. Ponyboy finds Johnny again and spends that night together. To their surprise, they encounter the two Soc girls' boyfriends who aim to beat them up. At this urgent moment, Johnny kills one of the Socs for self-defense. He and Ponyboy run away in fright and hide from the police in an old abandoned church on top of Jay Mountain with the help of another gang member. They spent several days in reading Gone with the Wind and exchanging their opinions on the poem Nothing Gold Can Stay. After days' introspection, they make up their minds to turn themselves in to the police. On their way to the police station, they see the church on fire when a school picnic is held there, and many kids are trapped in. Ponyboy and Johnny rush into the flaming church without a second thought and save all kids' lives. Ponyboy and Johnny are members of greasers, and Ponyboy describes them as, "Greasers are almost like hood; we steal things and drive old souped-up cars and hold up gas stations and have a gang fight once in a while" (Hinton, 2003, p. 3). However, going through the tragedy of manslaughter, they realize the significant meaning of social norms. Their gallant behavior of saving the kids who are in danger embodies their consciousness of behaving in a way that is acceptable to society. However, "Johnny's back was badly burned by a falling piece of timber and suffered from third-degree burns" (p. 102). The last words Johnny says to Ponyboy are, "fighting's no good..., and stay gold" (p. 148). Johnny persuades Ponyboy to remain gold on account of Johnny's consciousness of the harm of the fighting. Johnny fully realizes that "Ponyboy is better than the average hoodlum, and he wants Ponyboy to hold onto the golden qualities that set him apart from his companions" (SparkNotes, 2007). As well as in Johnny's last letter to Ponyboy, he says, "it's worth it. It's worth saving those kids. Their lives are worth more than mine, and they have more to live for" (p. 178). Johnny senses the invisible social norms that fighting is harmful and they should stay gold, complying with the social norms at the expense of his young life, and delivers this message to his peers, hoping to get them engaged in socialization together. Abraham Maslow once said that "suffering and sorrow always accompany growth" (Goble, 2006, p. 56). Downcast and despaired as he is, Ponyboy is inspired by his friend Johnny and understands that "it wasn't only a personal thing to me." He should "tell their side of story" to help his counterparts "who was mean and tough and hated the world" realize that "there was still good in it before it was too late" (Hinton, 2003, p. 197). Ponyboy decides to write down what has happened to him as a lower-class greaser. Combining his own experiences with his authentic and sincere idea, his heroic story put down in a book not only stimulates his own socialization, but also enlightens his counterparts' realization of staying gold. Socialization as a vital stage in the development of adolescence attaches great importance to the role of peers played in this process to inspire all adolescents to abide by the social norms. By doing so, the task of coming-of-age can finally be achieved.

\section{Socialization between Peers among Socs}

Bob is a Soc killed by Johnny out of self-defense. In the eyes of the greasers, he is a hooligan jumping and beating greasers up that all the greasers exasperate him. However, from the perspective of Randy, he considers Bob as a good guy. He says, "He was the best buddy a guy ever had" (Hinton, 2003, p. 116). The death of his best friend shocks him. It is the rumbles and fights that lead to the loss of his best buddy. Bob's death affects Randy a lot. He intends to give up rumbles and fights and determines not to let his father down again. Experiencing such a tragedy, Randy seems to realize the importance of social norms and understands why rumbles and fights would not be accepted by society. He says, "People get hurt in rumbles, maybe killed. I'm sick of it because it doesn't do any good" (pp. 116-117). Randy perceives the immorality of the fighting and the killing between greasers and Socs. Randy sighs that "Greasers will still be greasers and Socs will still be Socs, and sometimes I think it's the ones in the middle that are really the lucky stiffs" (p. 117). His peer's death enables him to realize the futility of the fighting and the killing between two gangs. Each 
group will not change their current status, only to pay the price for what they have done. At this moment, Randy gets himself involved in the process of socialization.

\section{Socialization between Peers among Two Hostile Groups}

Ponyboy and Randy can be called friends to some extent. Randy, the Soc who witnesses his best friend being killed by Johnny, is sick and tired of rumbles and fights. Being astonished to learn Ponyboy's heroic story, he gets into a conversation with Ponyboy frankly. What Ponyboy has done leaves a question mark to him about whether he would have saved those kids or not if he had been there. Randy as an adolescent is puzzled about this moral dilemma. He cannot choose the correct answer by himself. Through the communication with Ponyboy, Randy is properly guided by Ponyboy's viewpoints and values. Ponyboy says, "You would have saved those kids if you had been there, and you'd have saved them the same as we did" (Hinton, 2003, p. 117). The statement suggested and predicted by Ponyboy looks like a beacon light illuminating the way ahead for Randy. Under the inspiring remark from Ponyboy, Randy is convinced that he would do the same as Ponyboy do and be a hero himself. Maybe he is not a hero like Ponyboy, but just a hero behaving in a way that is acceptable to society.

\section{The RElationship BETWEen DE-EGOCENTRICITY AND SOCIALIZATION}

De-egocentricity is characterized by the understanding of others among adolescent individuals, which is the reflection of adolescents' internal coming-of-age, while socialization signifies the consciousness of social norms to behave in a way that is acceptable to society, which is observable external behaviors of coming-of-age. It can be comprehended that the understanding of others suggests interpersonal relationship which reflects adolescents' internal change of their coming-of-age, and the consciousness of social norms have a direct bearing on the adolescents' visible moral behaviors in the society which can be regarded as external change of their coming-of-age. They are interactive, interdependent and complementary. The internal change of adolescents' coming-of-age is conducive to the maturity of adolescents' intelligence and mentality, while the external change of it is beneficial to the standardization of adolescents' social behaviors. The balance of de-egocentricity and socialization is indispensable to the healthy development of adolescents.

\section{CONCLUSION}

Young adult literature was usually analyzed from the perspective of narrative structure, the archetype of major protagonists and culture (Rui Yuping, 2004). However, this paper, through a psychoanalytic study of Hinton's The Outsiders, reveals the crucial process of young adults' de-egocentricity and socialization so as to establish their own values and fulfill the task of coming-of-age, which reflects the major theme in young adult literature. With the combination of the theories of de-egocentricity and socialization, the study of The Outsiders provides a new perspective for the research of young adult fiction.

In particular, this paper discusses de-egocentricity and socialization of major protagonists in Hinton's The Outsiders, indicating that the essence of adolescent development is to undergo de-egocentricity so as to better understand others and socialization so as to raise social norms consciousness. The interaction between de-egocentricity and socialization exposes adolescents' achievement of coming-of-age and reveals the major theme of the novel "a heroic story of friendship, belonging" and development (Hinton, 2003, the back cover). This research into young adult literature from psychoanalytic aspect is only the tip of the iceberg, and more and more studies of Hinton's The Outsiders from different perspectives need to be carried out. I hope that the analysis in this paper is conducive to a profound understanding of Hinton's The Outsiders and renders the readers a deeper comprehension of young adult literature as a whole.

\section{REFERENCES}

[1] Arnett, J. J. (2001). Adolescence and emerging adulthood. New York: Prentice Hall.

[2] Colman, J. C. (1987). The nature of adolescence (G. C. Yang \& X. C. Yang Trans.). Hangzhou: Zhejiang People's Publishing House. (Original work published 1980).

[3] Enotes. (2007). Contemporary literary criticism. Retrieved November 26 ${ }^{\text {th }}$ 2007, from http://www.enotes.com/contemporary-literary-criticism/hinton-s-e.

[4] Goble, F. G. (2006). The third force: The psychology of Abraham Maslow (M. Lv \& H. W. Chen, Trans.). Shanghai: Shanghai Translation Publishing House. (Original work published 1969).

[5] Hinton, S. E. (2003). The outsiders. New York: Penguin Putnam Inc.

[6] Myers, D. G. (2005). Social psychology ( $8^{\text {th }}$ ed.). China: Posts and Telecom Press.

[7] Oxford advanced learner's English-Chinese dictionary. (2004). Beijing: The Commercial Press.

[8] Piaget, J. (1966). The language and the thought of children (M. Gabain, Trans.). Cleveland and New York: The World Publishing Company. (Original work published 1955).

[9] Piaget, J. (1981). The principle of genetic epistemology (X. D. Wang Trans.). Beijing: The Commercial Press. (Original work copyright 1972).

[10] Qi, L. (2006). The idea of television culture. Shanghai: Fudan University Press.

[11] Qian, W. L. (2001). Comment on Piaget's concept of children's egocentricism. Journal of Beijing University of Technology (Social Sciences Edition), 2(2), 67-71. 
[12] Rui, Y. P. (2004). Studies of American initiation stories. Beijing: China Social Sciences Press.

[13] Shaffer, D. R. (2004). Developmental psychology: Childhood and adolescence (6 ${ }^{\text {th }}$ ed.). China: China Light Industry Press.

[14] SparkNotes. (2007). The outsiders: Important quotation explained. Retrieved October 25 , 2007, from http://www.sparknotes.com/lit/outsiders/quotes.html.

[15] Steinberg, L. (2005). Adolescence ( $7^{\text {th }}$ ed.). New York: The McGraw-Hill Companies, Inc.

[16] Zhang, Y., \& Yang, Q. F. (2005). On the romantic colour in Hinton's new realist works. Journal of Jilin Normal University (Humanities and Social Science Edition). 33(1), 54-58.

Dan Shi was born in Ningbo, China in 1986. She received her MA in English Language Studies from The Hong Kong Polytechnic University, Hong Kong in 2009.

She is currently a PhD Candidate majoring in English Language Education in the Faculty of Education at The University of Hong Kong. Her main research areas are classroom discourse analysis and study of American initiation stories. 